\title{
Effectiveness of Conservative Physical Therapy Treatment with and Without Diaphragmatic Strengthening Exercises in Non Specific Low Back Pain
}

\author{
Arooj Munawar ${ }^{1}$, Rabiya Noor ${ }^{2}$, Ashfaq Ahmad ${ }^{3}$, Salman Bashir $^{4}$, Fahad Tanveer $^{5}$ \\ ${ }^{1}$ Senior Lecturer / Senior Physical Therapist, University Institute of Physical Therapy (UIPT), The University of Lahore \\ ${ }^{2}$ Assistant Professor, University Institute of Physical Therapy, The University of Lahore \\ ${ }^{3}$ Associate Professor, University institute of Physical Therapy, The University of Lahore \\ ${ }^{4}$ Associate Professor, University Institute of Physical Therapy \\ ${ }^{5}$ Assistant Professor, Shalamar Institute of Health Sciences, Lahore
}

\begin{abstract}
Non-specific low back pain is defined as low back pain not attributable to a recognizable, known specific pathology (e.g., infection, tumor, osteoporosis, fracture, structural deformity, inflammatory disorder, radicular syndrome, or caudaequina syndrome). Low back pain became one of the biggest problems for public health systems in the western world during the second half of the 20th century and now seems to be extending worldwide. Patients with chronic low back pain appear to have both abnormal position and a steeper slope of the diaphragm, which may contribute to the etiology of the disorder. The objective of the current study is to see effectiveness of conservative physical therapy treatment with and without diaphragmatic strengthening exercises in the treatment of nonspecific low back pain. It was a randomized clinical trial. Study was completed in Three months after the approval of synopsis. Simple random style sampling technique was used .A total number of 106 patients, 53 in each group included in this study calculated. The mean age of the patients in group $A$ was 45.36 5.88 the minimum age was 20 years and maximum was 60 years on the other side the mean age of the patients in group $B$ was $41.83 \pm 6.49$ the minimum age was 21 years and maximum was 58 years. In group $A$ there was significant difference in mean values of oswestry low back disability index at baseline and $3^{\text {rd }}$ week follow up as the p-value was significant where as in group $B$ there significant difference in mean values of Oswestry low back pain disability index. According to this research both the techniques conservative physical therapy treatment and conservative physical therapy treatment with diaphragmatic strengthening exercises were equally effective in the treatment of low back pain.
\end{abstract}

Keywords: Conservative Physical Therapy, Diaphragmatic Strengthening Exercise, Low Backache.

\section{Introduction}

\subsection{Overview}

Low back pain became one of the biggest problems for public health systems in the western world during the second half of the 20th century and now seems to be extending worldwide.[1, 2] Patients with chronic low back pain appear to have both abnormal position and a steeper slope of the diaphragm, which may contribute to the etiology of the disorder.[3] The lifetime prevalence of low back pain is reported to be as high as $84 \%$, and the prevalence of chronic low back pain is about $23 \%$, with $11-12 \%$ of the population being disabled by low back pain.[4] Patients suffering from chronic low back pain are often unsatisfied with conventional medical care and seek alternative therapies.[5] The diaphragm plays an important role in stabilizing the spine during balancing and loading tasks [6]
In a study conducted in year 2013, it was concluded that the diaphragm plays an important role in spinal control. [7] Bmode ultrasound appears to be a reliable means of determining the contractility of the diaphragm, an important muscle in spinal stability.[8] In a recent study, patients suffering from Chronic Low Back Pain (cLBP) improved significantly with breath therapy.[5] Nociceptive factors have a major role in acute pain conditions. [9] In chronic pain, psychosocial dimensions become relevant, and are important to explain how people respond to back pain.[10] The odds ratios (OR) for disc space narrowing and the presence of low back pain in men is $1.9(95 \%$ CI 1.4-2.8)[11] and OR greater than 2 have been reported for disc degeneration (OR $2 \cdot 18 ; 1 \cdot 4-3 \cdot 4)$ and for herniation (OR 2.07; 1·4-3·1).[12] Nerve growth factor extracted from degenerative nucleus pulposus might have a role in pain transmission, because nerve growth factor promotes axonal growth and induces substance $P$ production.[13] Findings from a meta-analysis that included cross-sectional and longitudinal studies show that people who are overweight or obese have an increased risk of low back

Volume 6 Issue 1, January 2017 


\section{International Journal of Science and Research (IJSR) \\ ISSN (Online): 2319-7064 \\ Index Copernicus Value (2015): 78.96 | Impact Factor (2015): 6.391}

pain, with the strongest association for care-seeking for low back pain, and for chronic low back pain.[14]

In cohort studies, only obesity was associated with an increased incidence of low back pain for a day or more in the previous 12 months (OR 1.53, 95\% CI 1·22-1·92). Research evidence to suggest that disuse and physical deconditioning are directly associated with chronic low back pain, in either a causal or consequential manner, is scarce.[15]

Cohort studies reveal a slight association between back pain and smoking status (OR for the increased incidence of low back pain in smokers is about $1 \cdot 3 ; 1 \cdot 11-1 \cdot 55)$, even when controlling for anxiety or mood disorders; [14] however, the underlying mechanisms remain obscure. The role of genetic factors has been widely discussed. Twin studies show that both low back pain and disc degeneration have a genetic background. Heritability estimates range from $30 \%$ to $46 \%$ for various types of back pain problem. Several other genetic effects have been reported through genes implicated in pain perception, signaling, psychological processing, and immunity.[16]

Interleukin-1 gene cluster polymorphisms are associated with Modic changes and might have a pathogenic role.[17] Genotype has also been reported to be associated with the outcome of surgery for degenerative disc disease.[18] One element that can obscure the pathogenic role of some risk factors is the presence of a non-linear relation with low back pain, as has been shown, for example, in the case of physical activity. A U-shaped relation-with a sedentary lifestyle and the pursuit of strenuous activities both associated with a greater risk of chronic low back pain-was reported in a Dutch population-based study.[19]

In a study of various disciplines, $5393 \%$ of clinicians reported that they treated patients differently in accordance with their own diagnoses. [20] In about $10-15 \%$ of patients, acute low back pain develops into chronic low back pain. The chronic state represents the greatest challenge because it tends not to improve with time and consumes most resources.[21] This study aims to provide an alternative method of treatment for non specific low back pain. And ultimately will add something new in the treatment of low back pain. As there is no specific equipment is required, so study is also cost effective. However, role of diaphragm can be evaluated by MSK ultrasound in future.

\subsection{Objectives}

The objective of the current study is to see effectiveness of conservative physical therapy treatment with and without diaphragmatic strengthening exercises in the treatment of non specific low back pain.

\subsection{Rationale}

The rationale of the study is to improve the health of patients with non specific low backache.

\subsection{Operational Definitions}

\subsubsection{Conservative Physical Therapy}

Conservative Physical Therapy includes physical therapy modalities including ultrasound, heat, William Flexion and Back extension Exercises

\subsubsection{Diaphragmatic Breathing Exercise:}

To perform this exercise while sitting in a chair:

1) Sit comfortably, with your knees bent and your shoulders, head and neck relaxed.

2) Place one hand on your upper chest and the other just below your rib cage. This will allow you to feel your diaphragm move as you breathe.

3) Breathe in slowly through your nose so that your stomach moves out against your hand. The hand on your chest should remain as still as possible.

4) Tighten your stomach muscles, letting them fall inward as you exhale through pursed lips. The hand on your upper chest must remain as still as possible.

Note: patient may notice an increased effort will be needed to use the diaphragm correctly. At first, he/she probably gets tired while doing this exercise. But keep at it, because with continued practice, diaphragmatic breathing will become easy and automatic.

How often should patient practice this exercise? At first, practice this exercise 5-10 minutes about 3-4 times per day. Gradually increase the amount of time you spend doing this exercise, and perhaps even increase the effort of the exercise by placing a book on your abdomen.

\subsubsection{Progressive Muscle Relaxation (Step By Step)}

Once you are comfortably supported in a quiet place, follow the instructions for each muscle group below (or just listen along to your recording):

1) To begin, take three deep abdominal breaths, exhaling slowly each time. Exhale; imagine that tension throughout your body begins to flow away.

2) Clench left fist. Hold for 7-10 seconds, and then release for 15-20 seconds. Repeat with the right fist. (Use the same time intervals for all muscle groups.)

3) Tighten forearms by straightening your fingers and pointing them at the ceiling, then back towards your body. Hold... and then relax.

4) Tighten biceps by drawing your forearms up towards your shoulders and "making a muscle." Hold... and then relax.

5) Shrug shoulders up towards your ears, tightening the muscles. Hold... and then relax.

6) Wrinkle up forehead and brow, focusing on the tension in the muscles... and then relax.

7) Squeeze eyes shut as tightly as you can, feeling the tension in the muscles around the eyes. Hold... and then relax.

8) Clench jaw, hard, flexing the muscles in your jaw and cheek. Hold... and then relax.

Volume 6 Issue 1, January 2017 


\section{International Journal of Science and Research (IJSR) \\ ISSN (Online): 2319-7064 \\ Index Copernicus Value (2015): 78.96 | Impact Factor (2015): 6.391}

9) Press lips together tightly, pursing them so the muscles around your mouth tighten... and then allow them to relax.

10) Press head back against the chair or bed, hard, feeling the tension in the back of your neck. Hold... and then relax.

\subsection{Materials and methods}

\subsubsection{Study Design}

The present study is a randomized Clinical Trial.

\subsubsection{Setting}

Data was collected from following physical therapy clinics and hospitals:

- University Physical Therapy \& Rehabilitation Clinic, Raiwind Road Campus, The University of Lahore (UOL)

- Physical Therapy \& Rehabilitation Clinic, University Teaching Hospital, UOL

- Nawaz Sharif Social Security Hospital, Multan Road, Lahore

- Mansoorah Hospital, Multan Road, Lahore

\subsubsection{Study Population}

Male and Female Patients with Non Specific Low back Pain.

\subsubsection{Duration of Study}

Study was completed in Three months after the

approval of synopsis.

\subsubsection{Sample size}

There were total 106 patients, 53 in each group. In our study we calculated sample size by using following formula[22]. The sample size had been calculated with $8 \%$ desired level of precision and 0.05 level of significance

\section{Formula applied:}

$$
\mathrm{n}=\mathrm{Z}^{2} \frac{\mathrm{p}(1-\mathrm{p})}{\mathrm{e}^{2}}
$$

$\mathrm{n}=$ sample size

$\mathrm{Z}^{2}=$ abscissa of normal curve that cuts off an area at the tails

(1-equals the desired confidence level e.g.95\%) which is 1.96

in above case

$\mathrm{e}=$ desired level of precision

$\mathrm{p}=$ prevalence

\subsubsection{Eligibility}

Inclusion Criteria

- All the people having age 20 to 60 years with either gender.

- LBP of musculoskeletal origin and non specific in nature

\section{Exclusion Criteria}

- Patients with red flags (e.g. Tumor, Fracture etc.)

- People having lumbar spine injury, disc pathologies

\subsubsection{Data collection}

The study was conducted in University Physical Therapy \& Rehabilitation Clinic, Raiwind Road Campus, The University of Lahore (UOL), Physical Therapy \& Rehabilitation Clinic,
University Teaching Hospital, UOL, Nawaz Sharif Social Security Hospital, Multan Road, Lahore, Mansoorah Hospital, Multan Road, Lahore which has about 112 patients at the start of study. 3 patients refused to participate in the study and 3 were not available during study duration. Remaining 106 patients were surveyed for BMI. 13 patients were found to be obese, 18 were overweight, 18 were under weight and remaining 57 were normal weighted. These were selected by simple random sampling using random number table that were matched in gender, marital status, diabetes, hypertension and occupational weight lifting. A pre-designed and detailed Questionnaire (Oswestry Disability Index) [23] was used to collect the relevant information from the subjects.

\subsubsection{Ethical consideration}

The ethical committee and Department of Medical Education of University Physical Therapy \& Rehabilitation Clinic, Raiwind Road Campus, The University of Lahore (UOL), Physical Therapy \& Rehabilitation Clinic, University Teaching Hospital, UOL, Nawaz Sharif Social Security Hospital, Multan Road, Lahore, Mansoorah Hospital, Multan Road, Lahore approved to conduct the study. Only those patients were included in the study who signed the written consent. All the personal information of participants were kept hidden.

\subsubsection{Statistical Procedure}

The Data was analyzed using SPSS v20.Mean \pm SD was calculated for numeric variables i.e. age BMI and frequency and percentage was shown with categorical variables e.g. Gender, marital status, diabetes and hypertension. The statistical differences between the means of variables in groups were compared with t-test. The statistical significance was set at $8 \%$ level.

\section{Results}

Table 1: Descriptive Statistics for Age

\begin{tabular}{|c|c|c|}
\hline & Group A & Group B \\
\hline Mean & 43.9434 & 44.9245 \\
\hline Std. Deviation & 12.37307 & 13.32269 \\
\hline Minimum & 20 & 21 \\
\hline Maximum & 60 & 58 \\
\hline
\end{tabular}

Group A: conservative physical therapy treatment alone

Group B: conservative physical therapy treatment with diaphragmatic strengthening exercises

The mean age of the patients in group A was $45.36 \pm 5.88$ the minimum age was 20 years and maximum was 60 years on the other side the mean age of the patients in group B was $41.83 \pm 6.49$ the minimum age was 21 years and maximum was 58 years .(Table-1) 


\section{International Journal of Science and Research (IJSR) \\ ISSN (Online): 2319-7064}

Index Copernicus Value (2015): 78.96 | Impact Factor (2015): 6.391

Table 2: Descriptive Statistics for Gender, BMI, Marital Status, Diabetes, Hypertension.

\begin{tabular}{|c|c|c|c|}
\hline Variable & Construct & Group A & Group B \\
\hline \multirow{3}{*}{ Gender } & Male & $32(60.38 \%)$ & $30(56.60 \%)$ \\
\cline { 2 - 4 } & Female & $21(39.62 \%)$ & $23(43.39 \%)$ \\
\hline \multirow{3}{*}{ BMI } & Underweight & $10(18.86 \%)$ & $8(15.09 \%)$ \\
\cline { 2 - 4 } & normal weight & $29(54.71 \%)$ & $28(52.83 \%)$ \\
\cline { 2 - 4 } & Overweight & $8(15.09 \%)$ & $10(18.86 \%)$ \\
\cline { 2 - 4 } & Obese patients & $6(11.32 \%)$ & $7(13.20 \%)$ \\
\hline Marital Status & Single & $19(35.8 \%)$ & $16(30.2 \%)$ \\
\cline { 2 - 4 } & Married & $34(64.2 \%)$ & $37(69.8 \%)$ \\
\hline Diabetes & Present & $21(39.6 \%)$ & $19(35.8 \%)$ \\
\hline & Absent & $32(60.4 \%)$ & $34(64.2 \%)$ \\
\hline Hypertension & Present & $24(45.3 \%)$ & $21(39.6 \%)$ \\
\hline & Absent & $29(54.7 \%)$ & $32(60.4 \%)$ \\
\hline Occupational & Yes & $11(20.8 \%)$ & $13(24.5 \%)$ \\
\hline Weight Lifting & No & $42(79.2 \%)$ & $40(75.5 \%)$ \\
\hline & Yes & $3(5.7 \%)$ & $0(\%)$ \\
\hline Alcohol & No & $50(94.3 \%)$ & $53(100 \%)$ \\
\hline & \multicolumn{2}{|}{}
\end{tabular}

Group A: conservative physical therapy treatment alone Group B: conservative physical therapy treatment with diaphragmatic strengthening exercises

There were $32(60.38 \%)$ males and $21(39.62 \%)$ female in group A and $30(56.60 \%)$ males and $23(43.39 \%)$ females in Group B. BMI Categories: Underweight $=<18.5$, Normal weight $=18.5-24.9$, Overweight $=25-29.9$, Obesity $=$ BMI of 30 or greater, In group A there were $10(18.86 \%)$ underweight, 29 (54.71\%) normal weight, 8 (15.09\%) overweight, 6 $(11.32 \%)$ Obese patients where as in group B there were 8 (15.09\%) underweight, 28 (52.83\%) normal, 10 (18.86\%) overweight, $7(13.20 \%)$ obese patients. In group A there were $10(18.86 \%)$ teachers, $(4(7.54 \%)$ dentist, $7(13.21 \%)$ social workers, $6(11.32 \%)$ business man, 9 (16.98\%) house wives, 8 $(15.09 \%)$ students, 5 (9.43\%) office workers, 4 (7.54\%) laborers while in group B there were $8(15.09 \%)$ teachers, 6 $(11.32 \%)$ dentist, 4 (7.55\%) social workers, 7 (13.21\%) business man,10 (18.87\%) house wives, 7 (13.21\%) students, 7 (13.21\%) office workers, $5(9.43 \%)$ laborers. In group A there were $4(7.54 \%)$ illiterate, $2(3.77 \%)$ under matric, 8 (15.09\%) matric or intermediate, $39(73.58 \%)$ graduate and above patients on the other side in group B there were $5(9.43 \%)$ illiterate, $1(1.88 \%)$ under matric, $9(16.98 \%)$ matric or intermediate, $38(71.69 \%)$ were graduate and above. In group A there were $13(22.64 \%)$ patients from lower class, 32 (52.83\%) from middle, 8 (11.32\%) from upper class where as in group B there were $11(20.75 \%)$ from lower class, 35 $(60.04 \%)$ from middle class and $7(13.21 \%)$ from upper class.

There were 19 (35.85\%) single and 34 (64.15\%) married patients in group A while in group B there were $16(30.18 \%)$ single and $37(69.81 \%)$ married patients. In group A There were $21(39.62 \%)$ patients with Diabetes and $32(60.37 \%)$ without diabetes where as in group b there were 19 (35.84\%) patients with diabetes and $34(64.15 \%)$ patients without diabetes. In group A there were 24 (45.28\%) hypertensive patients and $29(54.71 \%)$ non hypertensive patients where as in group B there were $21(39.62 \%)$ hypertensive and 32 (60.39\%)no hypertensive patients. There were 11 (20.75\%) patients in group A with occupational weight lifting and 43 $(81.13 \%)$ with no occupational weight lifting wile in group B there were $13(24.54 \%)$ with occupational weight lifting and $40(75.47 \%)$ with no occupational weight lifting. In group A there were $32(60.37 \%)$ smokers and $21(39.62 \%)$ non smokers while in group B there were $29(54.71 \%)$ smokers and $24(45.28 \%)$ non smokers. In group A there were 3 $(5.66 \%)$ drinkers and $50(94.33 \%)$ had never used alcohol where as in group There was no drinker. (Table-2)

Tables 3: Inferential statistics for Oswestry Low Back Disability Questionarrie

\begin{tabular}{|c|c|c|c|c|c|c|}
\hline & \multicolumn{3}{|c|}{ Group A } & \multicolumn{3}{c|}{ Group B } \\
\hline & Baseline & $3 r d$ week & $\begin{array}{c}p- \\
\text { value }\end{array}$ & Baseline & $3 r d$ week & $\begin{array}{c}p- \\
\text { value }\end{array}$ \\
\hline $\begin{array}{c}\text { Mean } \\
\text { Oswestry } \\
\text { Low Back } \\
\text { Pain } \\
\text { Disability } \\
\text { Index }\end{array}$ & $46.5 \pm 4.35$ & $38 \pm 2.56$ & $\mathbf{0 . 0 0 3}$ & $44.5 \pm 5.65$ & $31 \pm 5.56$ & $\mathbf{0 . 0 0 1}$ \\
\hline
\end{tabular}

Group A: conservative physical therapy treatment alone

Group B: conservative physical therapy treatment with diaphragmatic strengthening exercises

In group A there was significant difference in mean values of oswestry low back disability index at baseline and $3^{\text {rd }}$ week follow up as the p-value was significant where as in group B there significant difference in mean values of Oswestry low back pain disability index. (Table-3)

\section{Conclusion}

According to this research both the techniques conservative physical therapy treatment and conservative physical therapy treatment with diaphragmatic strengthening exercises were equally effective in the treatment of low back pain.

\section{References}

[1] El-Sayed, A.M., et al., Back and neck pain and psychopathology in rural Sub-Saharan Africa: evidence from the Gilgel Gibe Growth and Development Study, Ethiopia. Spine (Phila Pa 1976), 2010. 35(6): p. 684.

[2] Louw, Q.A., L.D. Morris, and K. Grimmer-Somers, The prevalence of low back pain in Africa: a systematic review. BMC Musculoskelet Disord, 2007. 8(1): p. 105.

[3] Koláŕ, P., et al., Postural function of the diaphragm in persons with and without chronic low back pain. journal of orthopaedic \& sports physical therapy, 2012. 42(4): p. 352-362.

[4] Balagué, F., et al., Non-specific low back pain. The Lancet, 2012. 379(9814): p. 482-491.

[5] Mehling, W.E., et al., Randomized controlled trial of breath therapy for patients with chronic low-back pain. Alternative Therapies in Health and Medicine, 2005. 11(4): p. 44. 


\section{International Journal of Science and Research (IJSR) \\ ISSN (Online): 2319-7064}

Index Copernicus Value (2015): 78.96 | Impact Factor (2015): 6.391

[6] Hodges, P.W. and S.C. Gandevia, Changes in intraabdominal pressure during postural and respiratory activation of the human diaphragm. Journal of applied Physiology, 2000. 89(3): p. 967-976.

[7] Janssens, L., et al., Greater diaphragm fatigability in individuals with recurrent low back pain. Respiratory physiology \& neurobiology, 2013. 188(2): p. 119-123.

[8] Harper, C.J., et al., Variability in diaphragm motion during normal breathing, assessed with B-mode ultrasound. journal of orthopaedic \& sports physical therapy, 2013. 43(12): p. 927-931.

[9] Kapellen, P.J. and D.P. Beall. Imaging evaluation of low back pain: important imaging features associated with clinical symptoms. in Seminars in roentgenology. 2010. Elsevier.

[10]Mannion, A.F., P. Dolan, and M.A. Adams, Psychological Questionnaires: Do "Abnormal" Scores Precede or Follow First-time Low Back Pain? Spine (Phila Pa 1976), 1996. 21(22): p. 2603-2611.

[11] de Schepper, E.I., et al., The association between lumbar disc degeneration and low back pain: the influence of age, gender, and individual radiographic features. Spine (Phila Pa 1976), 2010. 35(5): p. 531-536.

[12] Cheung, K.M., et al., Prevalence and pattern of lumbar magnetic resonance imaging changes in a population study of one thousand forty-three individuals. Spine (Phila Pa 1976), 2009. 34(9): p. 934-940.

[13] Yamauchi, K., et al., Nerve growth factor of cultured medium extracted from human degenerative nucleus pulposus promotes sensory nerve growth and induces substance $p$ in vitro. Spine (Phila $\mathrm{Pa} 1976), 2009$. 34(21): p. 2263-2269.

[14] Shiri, R., et al., The association between smoking and low back pain: a meta-analysis. The American journal of medicine, 2010. 123(1): p. 87. e7-87. e35.

[15] Verbunt, J.A., R.J. Smeets, and H.M. Wittink, Cause or effect? Deconditioning and chronic low back pain. Pain, 2010. 149(3): p. 428-430.

[16] Reimann, F., et al., Pain perception is altered by a nucleotide polymorphism in SCN9A. Proceedings of the National Academy of Sciences, 2010. 107(11): p. 51485153.

[17] Karppinen, J., et al., Modic changes and interleukin 1 gene locus polymorphisms in occupational cohort of middle-aged men. European spine journal, 2009. 18(12): p. 1963-1970.

[18]Dai, F., et al., Association of catechol-Omethyltransferase genetic variants with outcome in patients undergoing surgical treatment for lumbar degenerative disc disease. The Spine Journal, 2010. 10(11): p. 949-957.

[19] Heneweer, H., L. Vanhees, and H.S.J. Picavet, Physical activity and low back pain: a U-shaped relation? Pain, 2009. 143(1): p. 21-25.

[20] Kamper, S.J., et al., Treatment-based subgroups of low back pain: a guide to appraisal of research studies and a summary of current evidence. Best Practice \& Research Clinical Rheumatology, 2010. 24(2): p. 181-191.
[21] Krismer, M. and M. Van Tulder, Low back pain (nonspecific). Best Practice \& Research Clinical Rheumatology, 2007. 21(1): p. 77-91.

[22] Yamane, T., Statistics: an introductory analysis. 1967.

[23] Fairbank, J.C. and P.B. Pynsent, The Oswestry disability index. Spine (Phila Pa 1976), 2000. 25(22): p. 2940-2953.

Volume 6 Issue 1, January 2017 www.ijsr.net 